\title{
Sulfidation of pure and chromium-modified beta-NiAl intermetallic compound - mechanism studies
}

\author{
E. Godlewska and S. Mrowec
}

Institute of Materials Science, Academy of Mining and Metallurgy, al. Mickiewicza 30-059 Cracow, Poland

\begin{abstract}
The studies on sulfidation mechanism of pure and chromium modified $\beta-\mathrm{NiAl}$ intermetallic compound were carried out in $\mathrm{He} / \mathrm{S}_{2}$ gas mixtures at high sulfur pressure (about $2 \times 10^{3} \mathrm{~Pa}$ ). Gold markers were deposited on the surface of specimens prior to sulfidation run by a PVD process. The distribution of gold marker after sulfidation indicated that the outer scale layer, composed of sulfospinels, $\mathrm{NiAl}_{2} \mathrm{~S}_{4}$ and/or $\mathrm{CrAl}_{2} \mathrm{~S}_{4}$, and nickel sulfide, grows by an outward diffusion of cations. This is accompanied by an inward penetration of sulfur resulting in the formation of internal sulfides $\left(\mathrm{Al}_{2} \mathrm{~S}_{3}\right.$ and $\left.\mathrm{CrAl}_{2} \mathrm{~S}_{4}\right)$. The inward transport of sulfur may be due to dissociation of the sulfospinel phases at the scale/alloy interface. Secondary formation of fine-grained sulfospinel phases was observed in the vicinity of the scale/alloy interface. Another secondary reaction takes place between the sulfospinels and nickel sulfide nodules present on the scale surface, greatly contributing to the overall growth of the sulfospinel layer on $\beta-\mathrm{NiAl}$, $\mathrm{NiAl}-4 \mathrm{Cr}$ and NiAl-10Cr. The formation of a stratified scale on NiAl-20Cr is explained by periodic detachment of the scale layers and their reproduction on the alloy surface due to inward penetration of sulfur.
\end{abstract}

\section{Introduction.}

The physico-chemical properties of intermetallic compounds have been a subject of many investigations since they are considered as potential high temperature materials. The applicability of intermetallics is dependent on a number of parameters among which the most important are high mechanical strength, low creep, low thermal expansion, good workability, high oxidation/corrosion resistance. Selection based on these criteria indicates that the most promising materials for high temperature applications are the aluminides from the following systems: Ni-Al, Fe-Al, Ti-Al and Nb-Al. Attempts have been made to improve the properties of pure aluminides by various additions, such as: Y, Hf, $\mathrm{Zr}, \mathrm{B}, \mathrm{Si}, \mathrm{Cr}$ and V [1]. This work was aimed at getting more insight in the sulfidation behavior of pure and chromium modified $\beta$-NiAl by studying the mechanism of sulfide scale growth.

\section{Experimental.}

Materials used for the kinetic and mechanistic studies of sulfidation had the following nominal compositions in at\%: 50Ni-50Al (NiAl), 48Ni-48Al-4Cr (NiAl-4Cr), 45Ni-45Al-10Cr (NiAl$10 \mathrm{Cr}$ ) and $40 \mathrm{Ni}-40 \mathrm{Al}-20 \mathrm{Cr}(\mathrm{NiAl}-20 \mathrm{Cr})$. Alloy microstructures and chemical and phase compositions have been reported in previous papers [2, 3]. For the mechanistic studies a marker method has been chosen, in which the Au marker was deposited onto the surface of samples 
to be subsequently sulfidized. The samples, flat platelets, were ground on emery papers up to $600 \mu \mathrm{m}$ grit no., polished with diamond pastes, degreased and ultrasonically cleaned in alcohol. Only one of the flat surfaces was exposed to gold deposition which permitted comparison of scales formed on both sides of each sample after the sulfidation run. Immediately after the Au marker deposition the samples were sulfidized for about 2 hours at the temperature of $1273 \mathrm{~K}$ and sulfur pressure of $2 \times 10^{3} \mathrm{~Pa}$. Then they were mounted in epoxy resin and prepared for metallographic examination. The Au marker distribution was determined by EPMA. The sulfidation experiments were carried out in the earlier described [4] thermogravimetric set-up, in flowing $\mathrm{He} / \mathrm{S}_{2}$ gas mixtures. Oxygen level in the deoxidized carrier gas was $10^{-15}-10^{-10} \mathrm{~Pa}$. The phase and chemical compositions of sulfide scales and of the remaining alloy substrate were examined by means of X-ray diffraction, EPM, EDX, and SEM.

\section{Results and discussion.}

It has been reported in the previous papers [2, 3] that after some initial period the sulfidation process, for all the materials studied, could be approximated by a parabolic rate law:

$$
(\Delta m / A)^{2}=k t+C
$$

where $\Delta m$ is weight gain of the sample, $A$ - its surface area, $k$ - parabolic rate constant, $t$ time, $C$ - constant responsible for the initial non-parabolic reaction course. It has been found that the chromium containing alloys sulfidized faster than pure $\beta$-NiAl, their sulfidation rates increasing with chromium concentration in the alloy. Corrosion resistance of the studied materials increased with decreasing sulfur pressure and temperature. All the materials suffered from internal sulfidation, the extent of which was more pronounced at lower chromium contents. The internal sulfides precipitates consisted of $\mathrm{Al}_{2} \mathrm{~S}_{3}$ and $\mathrm{CrAl}_{2} \mathrm{~S}_{4}$. The relatively rapid degradation of these materials in sulfur rich environments at temperatures exceeding $1079 \mathrm{~K}$ resulted from poor protective properties of sulfospinel phases $\left(\mathrm{NiAl}_{2} \mathrm{~S}_{4}\right.$ and $\left.\mathrm{CrAl}_{2} \mathrm{~S}_{4}\right)$ constituting the major part of the sulfide scales. The latter, being a cation deficient sulfospinel, $\mathrm{Al}_{2 / 3} \square_{\mathrm{I} / 3}\left[\mathrm{Al}_{2-y} \mathrm{Cr}_{y}\right] \mathrm{S}_{4}$, appeared a particularly undesirable scale component due to its wide homogeneity range, $0.32<y<1.5$, large deviation from stoichiometry, 1/3 unoccupied tetrahedral sites, and ability to dissolve great amounts of foreign atoms, e.g. Ni, Mo, Co etc. $[5,6]$. In the scales examined in this work its composition ranged from $\mathrm{Ni}_{0.78} \mathrm{Al}_{1.53} \mathrm{Cr}_{0.63} \mathrm{~S}_{4}$ to $\mathrm{Ni}_{0.47} \mathrm{Al}_{0.91} \mathrm{Cr}_{1.39} \mathrm{~S}_{4}$. The composition of the $\mathrm{NiAl}_{2} \mathrm{~S}_{4}$ sulfospinel, in turn, ranged from $\mathrm{Ni}_{0.7} \mathrm{Al}_{2.3} \mathrm{~S}_{4}$ to $\mathrm{Ni}_{0.5} \mathrm{Al}_{2.5} \mathrm{~S}_{4}$. Calculations based on $\mathrm{X}$-ray diffraction studies have lead to the following approximated values of lattice parameters for this rombohedral phase: $a=3.61 \AA$ and $c=35.98 \AA$. A characteristic feature of sulfide scales formed on all the studied materials was the occurrence of $\mathrm{Ni}_{3} \mathrm{~S}_{2}$ outgrowths, being spherical nodules at temperatures exceeding the melting point of this phase, i.e. $1079 \mathrm{~K}$, or needles.

Figure 1 presents the results of marker experiments carried out with $\beta-\mathrm{NiAl}$ in order to determine its sulfidation mechanism. The microphotographs of scale cross-section accompanied by marker mapping and its concentration profile across the scale/metal interface, along the marked line, indicate that the Au marker is present exclusively in the external part of the metallic core, next to the alloy-scale interface and that it diffused into the substrate material during its exposure to the sulfidizing environment. Similar distribution of the Au marker was observed on other materials studied, which proves that the major part of the scales, built 
a)

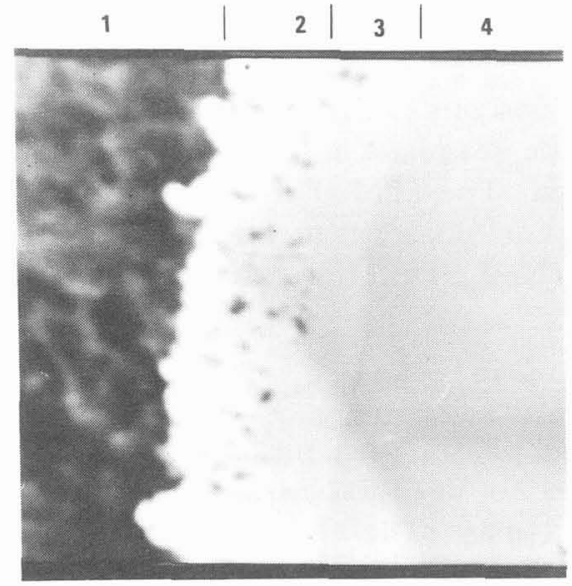

1- scale

2- internal sulfidation zone

$3-\beta-\mathrm{NiAl}_{\mathrm{Ni}}$

4- $\beta-\mathrm{NiAl}_{\mathrm{Al}}$
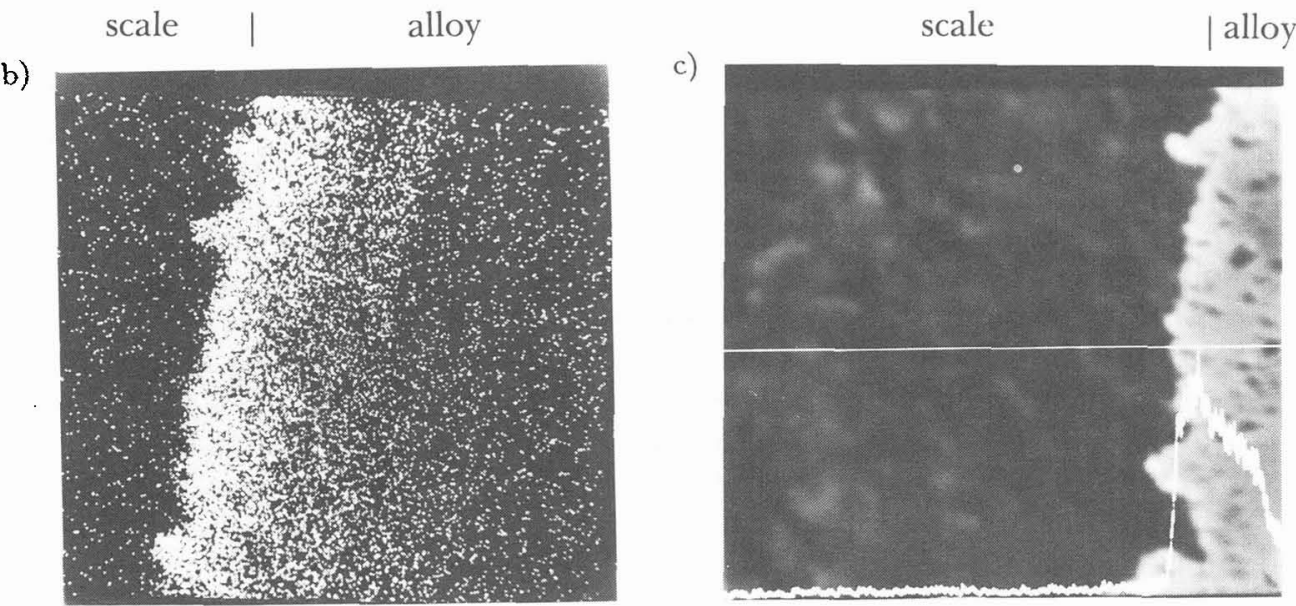

Fig. 1. - Distribution of Au marker in sulfide scale and across the alloy/scale interface for a $\beta$-NiAl sample sulfidized at $T=1273 \mathrm{~K}$ and $p_{S_{2}}=2 \times 10^{3} \mathrm{~Pa}: \mathrm{a}$ ) SEI image; b) Au mapping; c) Au concentration profile along the marked line

of sulfospinel phases, $\mathrm{NiAl}_{2} \mathrm{~S}_{4}$ and/or $\mathrm{CrAl}_{2} \mathrm{~S}_{4}$, grows by an outward diffusion of cations. The same holds for the superficial $\mathrm{Ni}_{3} \mathrm{~S}_{2}$ nodules or needles. In contrast, the internal sulfidation zone develops due to the inward diffusion of sulfur. This result is not surprising since both, chromium-aluminum sulfospinel and nickel sulfide, are much defected within the cation sublattice $[5,7]$ and nickel-aluminum sulfospinel, like many spinel-type compounds should also exhibit higher diffusivity for cations than for anions. Kinetic measurements together with the marker studies, careful examination of scale structures, electron microprobe and X-ray diffraction analyses of phase and chemical compositions of sulfide scales suggest that even if the scales grow predominantly by outward diffusion of cations, the detailed mechanisms of their formation may be complex and may involve some secondary processes.

In the simplest case, i.e. sulfidation of pure $\beta$-NiAl, the scale consists mainly of nickelaluminum sulfospinel, but it is coarse-grained in its outer part and fine-grained near the scale/alloy interface. Moreover, the shape of sulfospinel grains near the scale surface sug- 
gests that these were formed from the earlier existing nickel sulfide nodules. Since nickel sulfide does not form a continuous layer on the scale surface, the sulfospinel phase should grow with the participation of sulfur from the gaseous environment and its growth should be influenced by partial pressure of sulfur in the gas phase and not by the equilibrium sulfur pressure between the two phases considered. The EPM analysis has proved that nickel sulfide is practically Al-free whereas the sulfospinel phase, as mentioned above, is distinctly Al-rich. The reaction taking place at the $\mathrm{Ni}_{3} \mathrm{~S}_{2} / \mathrm{NiAl}_{2} \mathrm{~S}_{4}$ interface can be written as follows:

$$
1 / 3 \mathrm{Ni}_{3} \mathrm{~S}_{2}+2 \mathrm{Al}_{(\mathrm{s})}+5 / 3 \mathrm{~S}_{2}=\mathrm{NiAl}_{2} \mathrm{~S}_{4}
$$

where $\mathrm{Al}_{(s)}$ denotes aluminum in the sulfospinel phase. Since nickel sulfide is the source of nickel for the formation of $\mathrm{NiAl}_{2} \mathrm{~S}_{4}$, nickel does not need to be transported to the reaction front like aluminum, i.e. through the sulfospinel phase. Therefore it should be expected that Al diffusion in the sulfospinel phase is the rate determining step for the sulfide scale growth on $\beta-\mathrm{NiAl}$ as long as $\mathrm{Al}_{2} \mathrm{~S}_{3}$ does not develop a continuous film at the alloy/scale interface. The concentration profiles of nickel and aluminum in the sulfide scale support the proposed mechanism of scale growth, since nickel concentration increases and that of aluminum decreases toward the scale surface. Thus $\mathrm{Al}$ diffusion proceeds down its own concentration gradient. If nickel sulfide nodules did not participate in the above reaction, nickel diffusion to the reaction front would have to proceed against its concentration gradient (uphill diffusion). In the discussed case, however, the scale morphology indicates that a singificant part of the sulfide scale is formed at the cost of nickel sulfide nodules and actually there are no reasons for assuming anomalies in nickel diffusion.

Nickel diffusion in the surface layers of the metallic core, consisting of a Ni-rich $\beta$-NiAl $\left(\mathrm{NiAl}_{\mathrm{Ni}}\right)$ developed as a result of aluminum consumption, is faster than that of aluminum [8], causing the nickel supply to the alloy/scale interface to be faster than that of aluminum. In spite of this, no Ni-enrichment of the innermost scale region has ever been observed. In view of this fact, it should be expected that nickel transport to the scale surface where nickel sulfide nuclei constantly reappear, must proceed by some short-circuit diffusion paths, e.g. grain boundaries.

The fine-grained innermost part of the sulfide scale on $\beta$-NiAl develops due to the secondary dissociation processes of the sulfospinel phase. Sulfur activity at the alloy/scale interface exceeds the dissociation pressure of aluminum sulfide which promotes the formation of $\mathrm{Al}_{2} \mathrm{~S}_{3}$ nodules. These are thought responsible for worsening of the contact between the scale and the adjacent alloy, and for the initiation of secondary dissociation processes at this interface. In agreement with the dissociative model of scale growth [9], cations resulting from dissociation of the sulfospinel phase diffuse outward whereas sulfur reacts with the alloy producing fine-grained sulfospinel crystals in the metal consumption zone. In addition sulfur diffuses into the substrate and reacts with aluminum thus developing internal sulfidation zone. The proposed mechanism of sulfide scale growth is schematically shown in figure 2.

The sulfidation mechanism for alloys containing 4 and $10 \% \mathrm{Cr}$ is in many respects similar. The differences are essentially confined to phase composition of sulfide scales and be pointed out as follows:

- The scales are built of two sulfospinel phases, i.e. $\mathrm{NiAl}_{2} \mathrm{~S}_{4}$ and $\mathrm{CrAl}_{2} \mathrm{~S}_{4}$, the contribution of the latter increasing with chromium concentration in the alloy substrate.

- The sulfospinel layer in the nearest vicinity of the superficial $\mathrm{Ni}_{3} \mathrm{~S}_{2}$ nodules consists of $\mathrm{NiAl}_{2} \mathrm{~S}_{4}$, formed in the secondary reaction between this nickel sulfide and aluminum diffusing outwardly from the alloy through the mixed sulfospinel layer. The contribution of $\mathrm{CrAl}_{2} \mathrm{~S}_{4}$ in the scale increases toward the metallic core. 
(a)

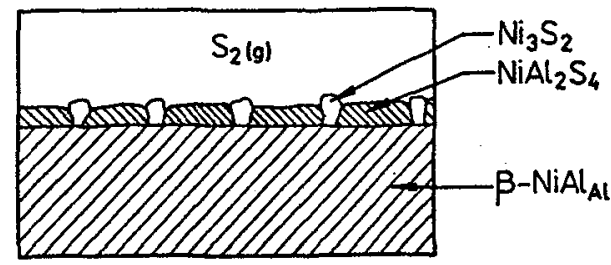

(b)

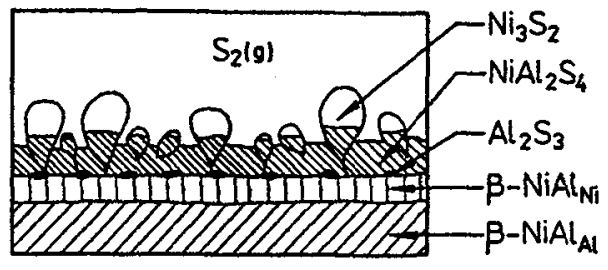

(c)

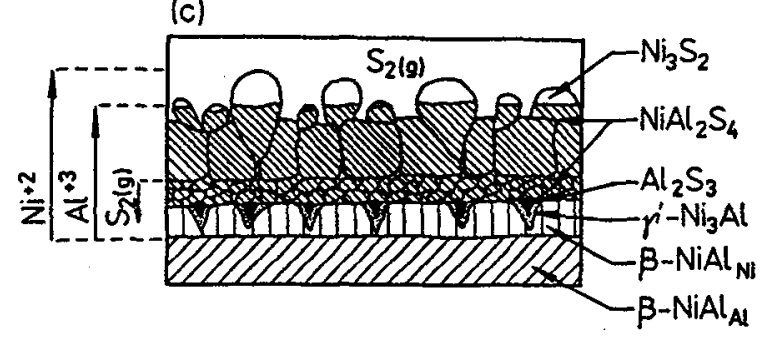

Fig. 2. - Scheme of sulfide scale growth on $\beta$-NiAl intermetallic compound at high sulfur pressures.

(a)
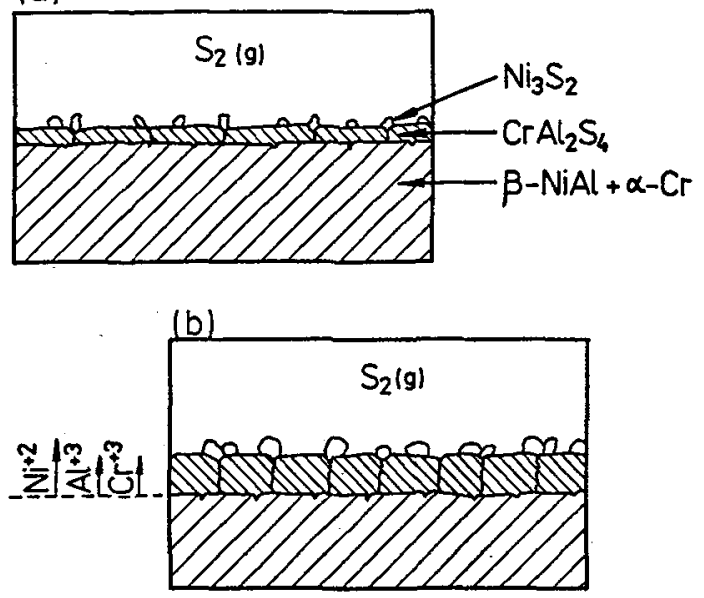
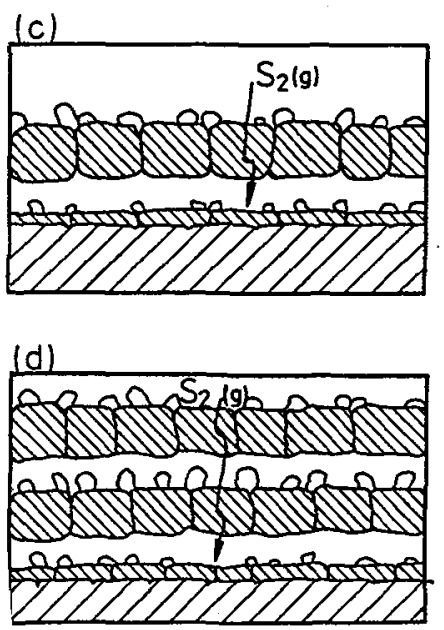

Fig. 3. - Scheme of sulfide scale growth on $\mathrm{NiAl}-20 \mathrm{Cr}$ alloy at high sulfur pressures.

- Internal sulfidation zone contains both, $\mathrm{Al}_{2} \mathrm{~S}_{3}$ and $\mathrm{CrAl}_{2} \mathrm{~S}_{4}$.

In the case of alloy containing $20 \% \mathrm{Cr}$ the phase composition and sulfidation mechanism is different (Fig. 3). The sulfospinel phase, being the predominant scale constituent, is Ni-rich $\mathrm{CrAl}_{2} \mathrm{~S}_{4}$. It coexists with nickel sulfide, $\mathrm{Ni}_{3} \mathrm{~S}_{2}$, which, however, is present not only at the scale surface but also inside the scale, in the form of bands separating much thicker sulfospinel layers. Scale microstructure does not show any evidence of secondary reactions between both phases. Moreover, nickel sulfide nodules are rather small as compared with those on other materials studied, which is probably related to the earlier-mentioned appreciable nickel solubility in the aluminum-chromium sulfospinel. The appearance of a stratified scale can be accounted for by its periodic detachment from the metallic core and reproduction of scale 


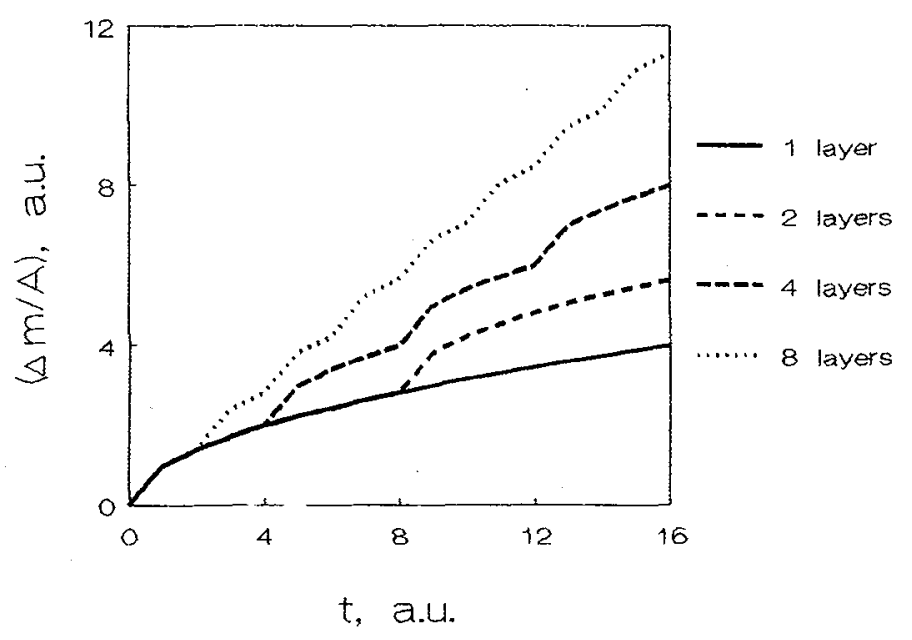

Fig. 4. - Effect of scale stratification on the shape of kinetic curve.

having the same sequence of layers on the alloy surface. The presence of nickel sulfide in the scale is conceivable if sulfur can somehow reach the innermost scale layer growing directly on the alloy surface, e.g. by penetrating through the microdiscontinuities of the earlier formed scale layers. Thus the scale grows by outward diffusion of cations up to the moment when some critical thickness is reached, depending on sample geometry and sulfidation conditions, and then it detaches from the metallic core. This critical thickness at $T=1173 \mathrm{~K}$ and $p_{\mathrm{S}_{2}}=$ $2 \times 10^{3} \mathrm{~Pa}$ is equal to about $60 \mu \mathrm{m}$. In accordance with the proposed mechanism of scale growth on NiAl-20Cr alloy, figure 4 illustrates the effect of the repeated scale detachment on the shape of kinetic curve, calculated with the assumption that the sulfidation process follows a parabolic rate law from the very beginning. As can be seen, the greater the stratification degree, the more frequent the acceleration of scale growth and the bigger deviations from the parabolic rate law. Finally, neglecting a certain initial period, we can approximate the kinetic curve with an equation

$$
(\Delta m / A)^{n}=k t+C,
$$

in which the exponent, $n$, can take the values from the interval [1-2], depending on the degree of scale stratification. It should be mentioned, however, that the periodically increasing sulfidation rate is not simply related to the repeated scale detachment. The model assumes sulfur access to the metallic core through the microdiscontinuities of the earlier developed scale layers. Thus, if nickel sulfide can be formed on the surface of the innermost sulfospinel layer, there are no reasons why it would not form in other regions through which sulfur penetrates, e.g. on the bottom sides of primary scale layers or elsewhere if only nickel activity is sufficiently high. 


\section{Concluding remarks.}

The course of sulfidation as well as phase composition of sulfide scales growing on $\beta$-NiAl and $\mathrm{NiAl}$-Cr pseudo-binary alloys depend not only on thermodynamics but also on the kinetics. The latter are responsible for the fact that at high sulfur pressures the most thermodynamically stable phase, $\mathrm{Al}_{2} \mathrm{~S}_{3}$, does not develop a continuous film at the metal/scale interface. The relatively high sulfidation rates can be accounted for by the formation of defected sulfospinel phases, $\mathrm{NiAl}_{2} \mathrm{~S}_{4}$ and/or $\mathrm{CrAl}_{2} \mathrm{~S}_{4}$, being predominant scale constituents. These sulfospinel phases and nickel sulfide nodules or crystals grow by outward diffusion of cations. Secondary reactions take place in sulfide scales formed on $\beta-\mathrm{NiAl}$ and $\mathrm{NiAl}-\mathrm{Cr}$ alloys containing 4 and $10 \% \mathrm{Cr}$. At the $\mathrm{NiAl}_{2} \mathrm{~S}_{4} / \mathrm{Ni}_{3} \mathrm{~S}_{2}$ interface, aluminum diffusing from the alloy through the sulfospinel layer reacts with $\mathrm{Ni}_{3} \mathrm{~S}_{2}$ and sulfur from the gas phase, and consequently the nickel sulfide nodules gradually transform into $\mathrm{NiAl}_{2} \mathrm{~S}_{4}$. At the alloy/scale interface, in turn, the kinetically retarded nucleation of $\mathrm{Al}_{2} \mathrm{~S}_{3}$ worsens the contact between the sulfospinel layer and the alloy which leads to scale dissociation. Thus liberated sulfur reacts again with the metallic core producing a fine-grained inner scale layer and it also diffuses into the alloy bringing about the development of the internal sulfidation zone. The scales on NiAl-20Cr, which consist of $\mathrm{CrAl}_{2} \mathrm{~S}_{4}$ and $\mathrm{Ni}_{3} \mathrm{~S}_{2}$, have a stratified structure. This stratification is ascribed to the repeated detachment of scale layers from the metallic core and their reproduction on the alloy surface due to inward penetration of sulfur through the discontinuities of the earlier formed scale layers, each layer growing by outward diffusion of cations untill it reaches some critical thickness.

\section{References}

[1] Kofstad P., Rahmel A., RapP R.A., Douglass D.L., Oxid. Met. 32 (1989) 125.

[2] Godlewska E., Godlewski K., Mrowec S., Mater. Sci. Eng. 87 (1987) 183.

[3] Godlewska E., Godlewski K., Mrowec S., Danielewski M., Mater. Sci. Eng. A120 (1989) 105.

[4] Rusiecki S., Wojtowicz A., Mrowec S., Przybylski K., Solid State Ionics 21 (1986) 273.

[5] Kovaliv V.I., Kesler J.A., Gordeev I.V., Trietiakov J.D., MielniK P.M., Neorg. Mater 17 (1981) 2084.

[6] Erdos E., Rahmel A., Oxid. Met. 26 (1986) 101.

[7] Kullerund G., Yund R.A., J. Petrol. 3 (1962) 126.

[8] JANSEN M.M.P., Metall. Trans. 4 (1973) 1623.

[9] Mrowec S., Corros. Sci. 7 (1967) 563. 